\title{
DIVERSIFIKASI PRODUK OLAHAN BERBASIS IKAN PATIN SEBAGAI POTENSI USAHA BAGI PANTI ASUHAN AL AMIN DAN SULTAN SURIANSYAH BANJARMASIN
}

\author{
Rizka Zulfikar dan Prihatini Ade Mayvita \\ Fakultas Ekonomi, Universitas Islam Kalimantan \\ Email : rizkazulfikar@gmail.com, ademayvita@gmail.com
}

\begin{abstract}
The ideal condition of an orphanage is not always to rely on donations from year to year, but the orphanage itself is capable of generating additional funds independently, so that the orphanage is expected to be entrepreneurial whose outcome can help the operation of the orphanage. One potential and profitable business to be worked on by the orphanage is the business of diversification product from cat fish such as nugget and sausage considering catfish raw material is quite available and become one of the mainstay fishery products in Banjarmasin. The orphanage partners in this PKM programme are Al Amin Orphanage and Sultan Suriansyah Banjarmasin Orphanage and based on observation, several problems of partners that have been identified are as follows : (1) unmotivated santri to entrepreneurship so that santri have level very low self-sufficiency, (2) lack of knowledge of caregivers about entrepreneurship and information about business potentials that can be utilized to improve the welfare of the orphanage. In this programme, PKM activities are (1) to provide nugget and catfish sausage processing training (2) to provide assistance in the production, packaging and marketing process (3) to motivate to cultivate and entrepreneurial spirit with holding entrepreneurship motivation training, (4) conducting financial management training in the form of cost of goods production and production facilities, packaging and marketing for start up business.
\end{abstract}

Keywords: Entrepreneurship, Cat Fish Products.

\begin{abstract}
ABSTRAK
Kondisi panti asuhan yang ideal adalah tidak selalu menggantungkan dana dari donasi para donatur dari tahun ke tahun, tetapi panti itu sendiri sudah mampu untuk menghasilkan tambahan dana secara mandiri, sehingga panti asuhan diharapkan dapat berwirausaha yang hasilnya dapat membantu operasional panti. Salah satu usaha yang berpotensi dan cukup menguntungkan untuk dapat digarap oleh panti adalah usaha pengolahan produk diversifikasi dari ikan patin seperti nugget dan sosis mengingat bahan baku ikan patin cukup tersedia dan menjadi salah satu produk perikanan andalan di Banjarmasin. Panti yang menjadi mitra dalam program PKM ini adalah Panti Asuhan Al Amin dan Panti Asuhan Sultan Suriansyah kecamatan Banjarmasin Utara Kotamadya Banjarmasin. Berdasarkan pengamatan maka beberapa permasalahan mitra yang berhasil diidentifikasi adalah sebagai berikut (1) belum termotivasinya para santri untuk berwirausaha sehingga para santri memiliki tingkat kemandirian yang masih sangat rendah, (2) minimnya pengetahuan para pengasuh akan kewirausahaan dan informasi tentang potensi-potensi usaha yang dapat dimanfaatkan untuk meningkatkan kesejahteraan panti. Dalam program kemitraan masyarakat ini, kegiatan-kegiatan PKM
\end{abstract}


yang diakukan antara lain adalah (1) memberikan pelatihan ketrampilan pengolahan nugget dan sosis ikan patin (2) memberikan pendampingan proses produksi, pengemasan dan pemasaran (3) memberikan motivasi untuk menumbuhkan dan menanamkan jiwa wirausaha dengan mengadakan training motivasi kewirausahaan, (4) mengadakan pelatihan manajemen keuangan berupa perhitungan harga pokok produksi dan bantuan sarana produksi, pengemasan dan pemasaran untuk start up usaha.

Kata kunci: Wirausaha, Produk Olahan Ikan Patin.

\section{PENDAHULUAN}

Produk berbasis ikan patin dinilai memiliki potensi sangat baik di Banjarmasin mengingat ikan patin merupakan produk perikanan yang banyak terdapat di daerah lahan rawa dan kota sungai seperti Banjarmasin. Selama ini dari produksi budidaya, produk yang dipasarkan adalah dalam bentuk segar dan belum banyak variasi dilakukan produk olahan dari ikan patin (Purnomo, 2014). Menurut BKPMD Propinsi Kalsel (2014), data produksi Patin di Propinsi Kalimantan Selatan pada tahun 2014 adalah 25,5 ribu ton. Volume ini setara dengan 6,3\% produksi patin nasional yang mencapai 403 ribu ton. Pada tahun 2015 kontribusi produksi ikan patin dari Kalimantan Selatan telah mencapai 48,6 ribu ton.

Produk olahan dari hasil usaha penangkapan dan budidaya ikan di wilayah Kalimantan Selatan sebenarnya sudah ada seperti produk amplang kerupuk ikan, namun kalau dilihat secara total produksi sangatlah tidak memadai sehingga daya jangkauan pasarnya pun hanya berkisar diwilayah yang tidak jauh dari daerah produksi dan juga belum adanya variasi olahanolahan yang lain dari ikan tersebut (Purnomo, 2014).

Saat ini usaha produk olahan ikan patin yang dihasilkan oleh masyarakat secara umum adalah ikan goreng, ikan bakar dan ikan pepes serta produk sampingannya, yaitu ikan kering, kerupuk dan amplang dengan hasil penilaian kualitasnya masih kurang diharapkan, hal ini karena produk yang dihasilkan kurang baik yang berdasarkan dari penilaian tekstur, warna, rasa dan aroma serta dengan kemasan yang kurang menarik.

Kecamatan Banjarmasin Utara merupakan salah satu kecamatan dari lima kecamatan yang ada di kota Banjarmasin dan terdiri dari 10 kelurahan dengaan luas wilayah 16,54 $\mathrm{Km} 2$. Di kecamatan ini terdapat 16 
Panti Asuhan yang tersebar di 10 kelurahan (BPS Banjarmasin, 2016).

Ada yang sedikit berbeda mengenai panti asuhan yang ada di kota Banjarmasin dengan yang berada di daerah Jawa. Panti asuhan di sini ratarata mungkin hampir keseluruhan, anak panti yang di asuh tidak selalu tinggal di panti asuhan itu sendiri. Tetapi ada yang masih tinggal di rumah orang tuanya (dhuafa, yatim/piatu). Dan tentunya ada yang langsung diasuh oleh panti yang dikarenakan anak tersebut yatim piatu atau dibuang orang tuanya. Sangat berbeda dengan fungsi panti asuhan sebenarnya yang menampung para anak-anak terlantar, yatim piatu dan lain-lain dengan membiayai pendidikan maupun penghidupannya selama di dalam panti.

Kondisi/keadaan panti asuhan di kota ini pun berbeda-beda, ada yang berupa yayasan yang ditopang oleh organisasi besar, ada yang merupakan yayasan yang berdiri sendiri. Sehingga terlihat sekali mana-mana panti yang terlihat sudah mapan, dan mungkin ada yang sangat pas-pasan dalam membiayai para anak panti yang diasuhnya. Kondisi panti asuhan yang ideal adalah sudah mampu untuk menghasilkan tambahan dana secara mandiri, sehingga tidak terlalu tergantung kepada para donatur sehingga panti perlu memiliki usaha yang dapat menopang operasional panti. Meskipun diakui bahwa untuk memulai suatu usaha maka diperlukan pengetahuan dan motivasi kewirausahaan bagi pengelola dan penghuni panti.

Panti yang menjadi mitra dalam program PKM ini antara lain adalah Panti Asuhan Al Amin di Kelurahan Sungai Miai dan Panti Asuhan Sultan Suriansyah di kelurahan Kuin Utara kecamatan Banjarmasin Utara Kotamadya Banjarmasin yang hingga saat ini masih belum memiliki usaha dan masih sangat tergantung kepada para donatur. Berdasarkan hal tersebut di atas maka merupakan peluang usaha bagi panti mitra PKM untuk memiliki usaha di bidang pengolahan ikan patin dengan variasi produk yang disesuaikan dengan kesukaan konsumen saat ini, yaitu nugget dan sosis patin.

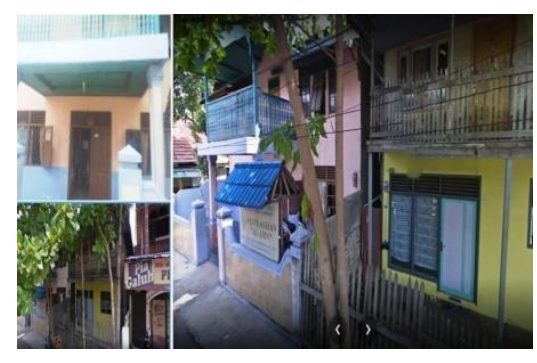

(1) Panti Asuhan Al Amin 


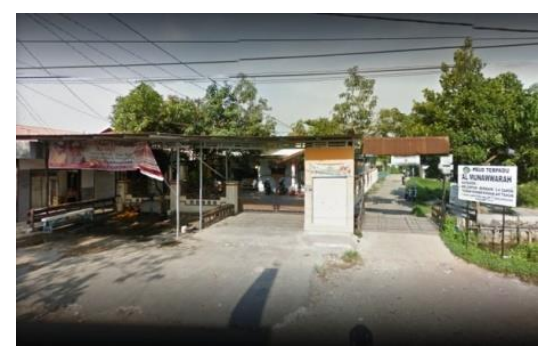

(2) Panti Asuhan Sultan Suriansyah

Tujuan kegiatan kemitraan masyarakat ini adalah memberikan pelatihan ketrampilan pengolahan produk nugget dan sosis ikan patin (2) memberikan pendampingan dalam proses produksi, pengemasan, dan pemasaran (3) memberikan motivasi untuk menumbuhkan dan menanamkan jiwa wirausaha dengan mengadakan training motivasi kewirausahaan, (4) mengadakan pelatihan manajemen keuangan berupa perhitungan harga pokok dan memberikan bantuan sarana produksi, pengemasan dan pemasaran untuk start up usaha.

Sedangkan manfaat yang diharapkan dari kegiatan ini adalah agar para anak-anak panti memiliki ketrampilan dan pengetahuan mengenai pengolahan produk nugget dan sosis ikan patin yang selanjutnya menjadi bekal untuk berwirausaha yang diharapkan dapat menopang operasional panti.

\section{METODE KEGIATAN}

Kegiatan program kemitraan masyarakat ini dilaksanakan paada bulan Juli hingga Agustus 2018, dimana metode pelaksanaan kegiatan ini dilakukan dalam 3 tahapan yaitu (1) tahap persiapan, (2) tahap kegiatan, dan (3) tahap pendampingan Tahap persiapan dilakukan dengan mengadakan survey pendahuluan ke lokasi mitra. Survei dilakukan untuk mengetahui kesediaan mitra untuk bekerjasama dengan tim pengusul dan untuk mengetahui permasalahan mitra, menetapkan solusi bersama yang akan dilaksanakan, waktu pelaksanaan, menentukan kriteria anak panti yang akan dijadikan peserta kegiatan dan mendiskusikan strategi yang akan dilakukan dalam kegiatan. Khalayak sasaran dari kegiatan ini adalah 10 orang anak panti sebagai perwakilan penghuni panti.

Tahap kegiatan berisikan kegiatankegiatan seperti pelatihan pengolahan produk nugget dan sosis patin, pelatihan pengemasan vakum, pelatihan manajemen keuangan, pelatihan pemasaran dan training motivasi kewirausahaan. Sedangkan tahap pendampingan berisikan kegiatan 
pendampingan dalam hal pemasaran, pengurusan perijinan dan pengelolaan keuangan.

Proses pengolahan nugget ikan patin mengikuti komposisi bahan hasil penelitian Nafiah dkk (2012) yang menggunakan tepung terigu $30 \%$ dan karagenan $1.5 \%$ dari berat adonan karena komposisi bahan menghasilkan tekstur yang disukai oleh panelis sedangkan sosis ikan menggunakan komposisi bahan hasil penelitian Ramasari (2012) yang menggunakan tepung tapioka $15 \%$ dan karagenan $1.5 \%$ dari berat adonan karena komposisi ini akan menghasilkan sosis ikan yang memiliki tekstur, rasa dan warna yang disukai panelis.

Sedangkan prosedur pengolahan nugget dan sosis ikan patin yang digunakan dalam kegiatan ini mengikuti alur penelitian yang disarankan oleh Purnomowati (2012)sebagai berikut :

\section{Prosedur Pembuatan Nugget Ikan}

Patin

- Daging ikan patin direndam dalam susu cair dengan perbandingan larutan 1:1, diangkat dan ditiriskan dan selanjutnya disimpan di dalam lemari es selama 1 jam untuk menghilangkan bau tanah yang biasa terdapat pada ikan (Purnomowati, 2012).

- Daging ikan, tepung tapioka, telur, bawang putih, merica, garam dan gula pasir dicampur dan diaduk rata. Disiapkan loyang loaf (persegi empat panjang) kecil, dialasi aluminium foil dan diolesi tipis dengan minyak. Adonan ikan dituang, permukaannya diratakan, dikukus hingga matang (30 menit). Adonan yang sudah dikukus dikeluarkan dari loyang, lalu dipotong-potong persegi atau sesuai selera. Potongan ikan kemudian dilumuri tipis dengan tepung terigu, dicelupkan ke dalam telur. Kemudian diangkat, lalu dilumuri tipis tepung roti.

- Proses dilanjutkan dengan penggorengan yaitu : nugget ikan digoreng hingga kuning.

\section{Prosedur Pembuatan Sosis Ikan}

\section{Patin}

- Daging ikan patin direndam dalam susu cair dengan perbandingan larutan 1:1, diangkat dan ditiriskan dan selanjutnya disimpan di dalam lemari es selama 1 jam untuk menghilangkan bau tanah yang biasa terdapat pada ikan 
(Purnomowati, 2012).

- Daging ikan digiling hingga lumat / halus. Tambahkan garam sedikit demi sedikit pada daging yang telah halus dan diaduk hingga merata. Masukkan minyak goreng, aduk terus sampai tercampur rata. Tambahkan tepung tapioka sedikit demi sedikit sambil terus diaduk. Kemudian berturut-turut masukkan gula halus, merica halus, condiment, bumbu masak, dan putih telur dan diaduk sampai homogen. Masukkan bongkahanbongkahan es batu pada saat pencampuran atau pengadukan, sehingga diperoleh sosis ikan dengan elastisitas yang baik. Adonan yang telah siap dimasukkan ke dalam "stufler" lalu isikan ke dalam casing (usus kambing) dengan cara menekan /menyemprotkan. Tentukan ukuran panjang sosis yaitu kira-kira $4-6 \mathrm{~cm}$, kemudian ikat dengan benang, biarkan sampai beberapa ikatan.

- Perebusan sosis ikan dilakukan dengan cara merebus sosis ke dalam air panas dengan suhu +60 C selama 20 menit. Kemudian rebus kembali dalam air panas dengan suhu $90 \mathrm{C}$ hingga matang. Setelah matang angkat dan tiriskan.

\section{HASIL KEGIATAN DAN LUARAN}

\section{A. Tahap Persiapan}

Adapun tahap persiapan dilakukan antara lain adalah : (1) Permintaan kesediaan mitra 1 dan mitra 2 pada tanggal 25 Juni 2017, (2) Diskusi tentang tahapan dan pelaksanaan kegiatan pada tanggal 15 April 2018 dan dikarenakan adanya masih adanya kegiatan Ujian sekolah dan Ulangan Umum di sekolah para santri serta kegiatan bulan Ramadhan, maka disepakati bahwa pelaksanaan dilakukan mulai bulan Juli 2018, (3) Konfirmasi pelaksanaan kegiatan pada tanggal 10 Juli 2018 dan disepakati bahwa pelaksanaan kegiatan dimulai pada tanggal 13 Juli 2018 (mitra 1) dan tanggal 15 Juli 2018 (mitra 2) dan (4) Pembelian bahan utama, bahan penunjang, mesin dan peralatan pengolah produk nugget dan sosis seperti blender, timbangan, peralatan stainless, mesin pengemas vakum, mesin pengolah sosis dan freezer. 


\section{B. Tahap Pelaksanaan Kegiatan}

\section{B.1. Pelatihan dan Praktek} Pengolahan Produk Pangan dari

\section{Ikan Patin}

Pada tahap ini kegiatan yang dilakukan adalah :

1) Pengolahan Nugget Ikan di Panti $\mathrm{Al}$ Amin, pada tanggal 13 Juli 2018 yang diikuti oleh pengasuh panti dan 10 orang penghuni panti yang terdiri dari 5 orang peserta laki-laki dan 5 orang peserta perempuan. Peserta kegiatan adalah penghuni panti $\mathrm{Al}$ Amin yang sudah duduk di bangku sekolah menengah atas. Agenda dalam kegiatan ini antara lain:

a. Pembukaan,

b. Pengenalan bahan utama dan bahan penunjang untuk mengolah produk nugget ikan,

c. Pengetahuan tentang komposisi bahan utama dan penunjang yang terdiri dari:

1. Ikan Patin $=1 \mathrm{Kg}$

2. Tepung Terigu $(30 \%)=300 \mathrm{gr}$

3. Karagenan $(1.5 \%)=15$ gram

4. Telur ayam $=8$ butir

5. Susu skim $=2$ sendok the

6. Bawang Putih $=6$ siung

7. Bawang Bombay $=1$ siung

8. Merica Bubuk $=1$ bungkus

9. Garam Halus $=1$ sendok makan
10. Kaldu ayam $=1$ bungkus

11. Tepung Roti $=100$ gram

Kegiatan pengolahan nugget ikan patin terdiri dari tahapan persiapan bahan utama dan bahan penunjang seperti mengambil daging ikan, menimbang, penyiapan bumbu, pencampuran, pengadukan, pengukusan, pencetakan, pelumuran nugget dengan tepung roti hingga penggorengan.

Gambar pelaksanaan kegiatan di panti asuhan $\mathrm{Al}$ Amin dapat dilihat pada gambar-gambar berikut ini:

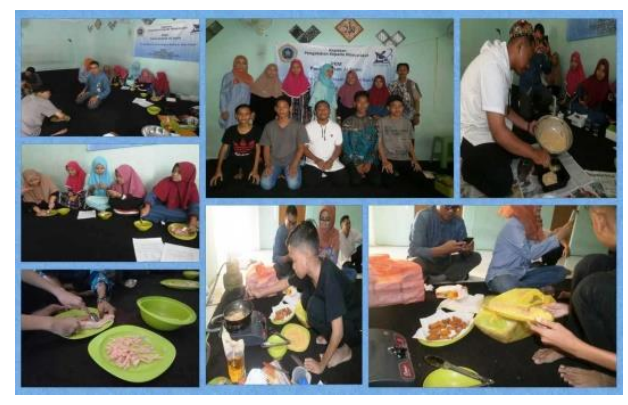

\section{Gambar 1. Pelatihan Pengolahan}

\section{Nugget Ikan Patin di Panti Al Amin}

2) Pengolahan Sosis Ikan Patin di Panti Sultan Suriansyah

Dilakukan pada tanggal 14 Juli 2018 yang diikuti oleh pengasuh panti dan 10 orang penghuni panti yang terdiri dari 5 orang peserta lakilaki dan 5 orang peserta perempuan. Seluruh peserta kegiatan adalah penghuni panti Sultan Suriansyah 
yang sudah duduk di bangku sekolah menengah atas.

Agenda dalam kegiatan ini antara lain adalah :

a. Pembukaan,

b. Pengenalan bahan utama dan bahan penunjang,

c. Pengetahuan tentang komposisi bahan utama dan penunjang, yang terdiri dari:

1) Ikan Patin $=1 \mathrm{Kg}$

2) Tepung Tapioka $=150 \mathrm{gr}$

3) Karagenan $=15 \mathrm{gr}$

4) Minyak goring $=50 \mathrm{ml}$

5) Susu Skim $=2$ sendok teh

6) Garam $=1$ sendok makan

7) Bawang Putih $=6$ siung

8) Gula $=1$ sendok makan

9) Lada/merica bubuk $=1$ bungkus

10) Air es $=200 \mathrm{ml}$

Pelaksanaan kegiatan pengolahan sosis ikan patin terdiri dari tahapan persiapan bahan utama dan bahan penunjang seperti mengambil daging ikan, menimbang, penyiapan bumbu, pencampuran, pengadukan, pengisian adonan ke dala casng sosis, perebusan tahap I dan tahap II.

Gambar pelaksanaan kegiatan di panti asuhan Sultan Suriansyah dapat dilihat pada gambar-gambar berikut ini :

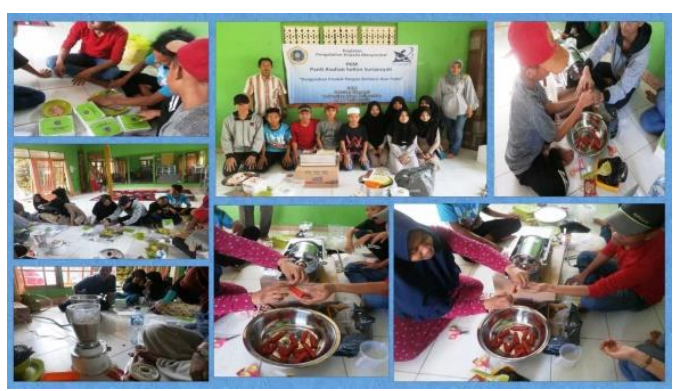

Gambar 2. Pelatihan Pengolahan

Sosis Ikan Patin di Panti Sultan

Suriansyah

\section{B.2. Pelatihan Pengemasan dan Pemasaran Produk Pangan Nugget dan Sosis Ikan}

Kegiatan ini dilaksanakan pada tanggal 28 dan 29 Juli 2018 berupa kegiatan pelatihan penggunaan mesin pengemas vakum untuk meningkatkan daya simpan produk sosis dan nuggget ikan patin.

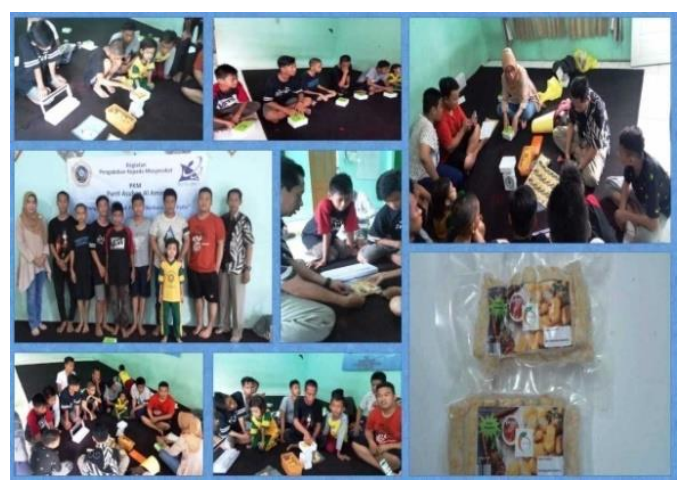




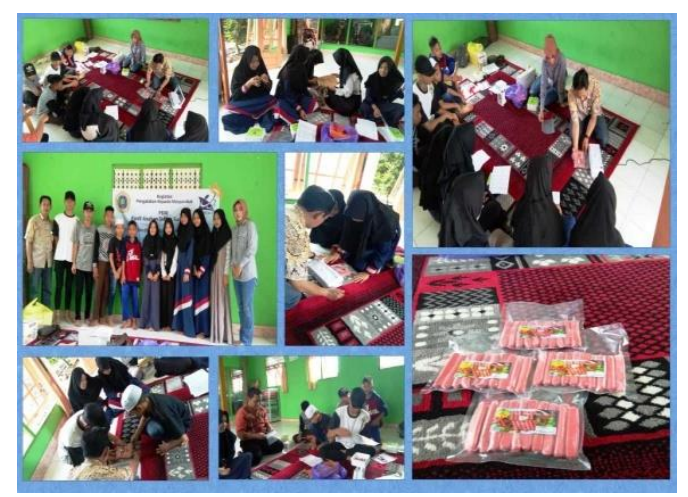

Gambar 3. Pelatihan Pengemasan

Vakum di Panti Al Amin dan Sultan

Suriansyah.

\section{B.3. Training Kewirausahaan}

Kegiatan training kewirausahaan dilaksanakan pada tanggal 28 - 29 Juli 2018. Materi yang disampaikan antara lain adalah pentingnya berwirausaha, faktor-faktor penunjang keberhasilan kewirausahaan dan kendala yang biasa dihadapi dalam berwirausaha. Narasumber menyampaikan bahwa wirausaha dapat dimulai dari sesuatu yang disenangi atau hobby dan mencoba mencari ciri khas tersendiri dari usaha yang akan dijalani agar memiliki perbedaan dengan usaha lain yang sejenis. Selain itu, dalam berwirausaha agar selalu berorientasi kepada pelanggan dan menggali potensi produk yang akan dikembangkan agar usaha tidak monoton dan terus berkreasi dengan ide-ide baru dan inovasi yang menunjang perkembangan produk.

Dalam berwirausaha juga harus tidak takut akan merugi dan tidak gampang menyerah jika menghadapi kendala usaha. Dijelaskan bahwa para enterpreneur yang berhasil adalah mereka yang terus mencoba bangkit dari setiap kegagalan dan menjadikan setiap kegagalan sebagai suatu pelajaran yang berharga. Dalam mengembangkan produk hendaknya selalu konsisten dengan kualitas produk agar tercipta kesetiaan pelangggan yang menjadi konsumen produk yang dihasilkan.

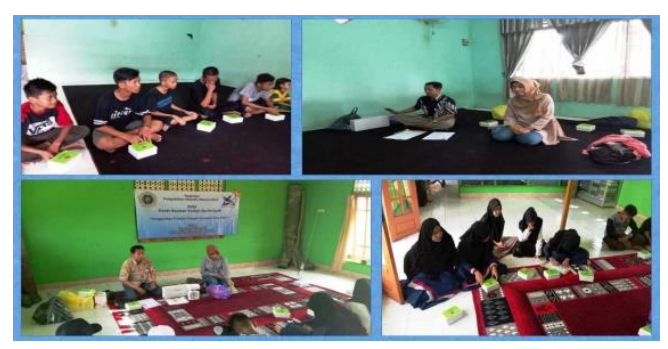

Gambar 5. Training Kewirausahaan

\section{B.4. Pendampingan Pemasaran}

Kegiatan pendampingan pemasaran yang telah dilakukan 
dalam rangka membantu proses pemasaran produk-produk hasil kegiatan antara lain adalah mendisain stiker kemasan produk dan memasarkan produk nugget dan sosis melalui event pekan ilmiah Universitas Islam Kalimantan MAB Banjarmasin yang berlangsung pada tanggal 16 - 19 Juli 2018 melalui stand UPT Kewirausahaan dan Inkubator Bisnis Uniska. Hasil yang diperoleh dalam proses pendampingan pemasaran ini cukup menggembirakan karena berhasil menjual 15 pcs produk nugget dan 15 pes produk sosis ikan patin.

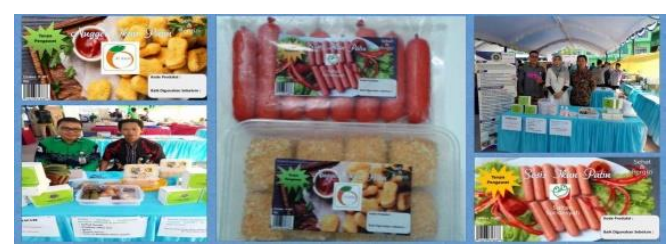

Gambar 6. Dampingan Pemasaran

Produk Hasil Kegiatan.

\section{B.5. Pelatihan Manajemen}

Keuangan dan Permodalan

Kegiatan ini dilaksanakan pada tanggal 28 - 29 Juli 2018 yang berisikan penjelasan mengenai cara menentukan harga pokok produksi, penentuan harga jual, perhitungan keuntungan usaha dan seputar permodalan.

Gambaran perhitungan harga pokok produksi dan perhitungan keuntungan usaha nugget dan sosis ikan patin adalah sebagai berikut :

Tabel 1. Analisis Harga Pokok Produksi Nugget dan Sosis Ikan Patin per Kg Bahan Baku

\begin{tabular}{clcc}
\hline No & \multicolumn{1}{c}{ Uraian } & $\begin{array}{c}\text { Produk } \\
\text { Nugget }(\text { Rp) }\end{array}$ & $\begin{array}{c}\text { Produk Sosis } \\
(\text { Rp) }\end{array}$ \\
\hline 1 & Output & $\begin{array}{c}5 \mathrm{Bks} / 200 \\
\text { gram }\end{array}$ & $5 \mathrm{Bks} / 200$ gram \\
2 & Harga Jual/bks & 20,000 & 20,000 \\
3 & Total Penjualan (A) & 100,000 & 100,000 \\
4 & Biaya Tetap (B) & 15,000 & 20,000 \\
& (sewa peralatan \& tempat) & 52,500 & 49,500 \\
5 & $\begin{array}{l}\text { Biaya Variabel (Bahan Baku, } \\
\text { Tenaga Kerja, Listrik \& Gas }\end{array}$ & & \\
& Kemasan, Pemasaran) (C) & & \\
& & &
\end{tabular}




\begin{tabular}{clcc}
6 & Total Biaya $(\mathrm{D}=\mathrm{B}+\mathrm{C})$ & 67,500 & 69,500 \\
7 & Keuntungan $(\mathrm{A}-\mathrm{D})$ & 32,500 & 30,500 \\
8 & Gross Profit Margin & $33 \%$ & $31 \%$ \\
9 & BEP Produksi (Bungkus) & $3 \mathrm{Bks}$ & $4 \mathrm{Bks}$ \\
& & $(600 \mathrm{Gram})$ & $(800 \mathrm{Gram})$ \\
10 & BEP Penjualan (Rp) & 60,000 & 80,000 \\
\hline
\end{tabular}

Berdasarkan gambaran harga pokok produksi dan perhitungan keuntungan, maka usaha pengolahan nugget dan sosis ikan patin dinilai cukup menguntungkan dengan tingkat keuntungan diatas $30 \%$ sehingga kedua produk olahan dinilai memiliki prospek dan potensi untuk dikembangkan oleh mitra PKM guna mendukung keuangan operasional panti.

\section{Tahap Evaluasi}

Evaluasi pelaksanaan kegiatan yang dilakukan antara lain adalah sebagai berikut :

- Memberikan kuesioner tentang pelaksanaan kegiatan untuk mengevaluasi kinerja tim pelaksana PKM.

- Mengadakan pengamatan langsung di lapangan terhadap jalannya kegiatan start up usaha mitra.

- Memonitor perkembangan hasil kegiatan yaitu kendala yang dihadapi dan jangkauan pasar.

\section{Luaran Kegiatan}

Adapun luaran yang dihasilkan dari kegiatan ini antara lain adalah :

1. Adanya publikasi pada media online seperti facebook dan website UPT Kewirausahaan Uniska MAB Banjarmasin (Http://UKIB.Uniskabjm.ac.id)

2. Peningkatan penerapan IPTEK pada masyarakat berupa pemberian pengetahuan tentang penggunaan susu skim untuk menghilangkan bau tanah pada ikan patin (Purnomowati, 2012), komposisi bahan untuk optimalisasi produk nugget dan sosis ikan patin, Penggunaan tepung pengenyal untuk meningkatkan tekstur produk nugget dan sosis ikan patin (Nafiah dkk, 2012; Ramasari dkk, 2012) 
3. Diversifikasi produk berupa pengolahan produk berbasis ikan patin menjadi produk frozrn food seperti nugget dan sosis.

4. Perbaikan tata nilai masyarakat berupa pemberian wawasan kepada mitra tentang pentingnya

kewirausahaan dan meningkatkan motivasi mitra untuk memiliki usaha sendiri agar tidak terlalu tergantung pada para donatur.

\section{Kendala dan Solusi}

Dalam melaksanakan kegiatan ini kendala yang dihadapi antara lain adalah (1) terbatasnya daya listrik mitra sehingga freezer untuk penyimpanan produk tidak bisa secara kontinu dioperasikan dan terbatasnya waktu kegiatan yang menyebabkan proses pendampingan pemasaran serta proses pengurusan perijinan belum maksimal dilakukan, (2) kondisi dapur panti yang masih perlu dilakukan pembenahan dan renovasi untuk mendukung proses pengolahan produk nugget dan sosis ikan, khususnya dalam hal kebersihan.

Solusi yang dapat dilakukan adalah tetap memberikan pendampingan pemasaran kepada mitra PKM untuk pemasaran dengan sistim by order (pesanan) sehingga tidak diperlukan persediaan produk sedangkan untuk perijinan akan tetap diproses mengikuti prosedur instansi setempat.

\section{KESIMPULAN DAN SARAN}

\section{Kesimpulan}

Beberapa hal yang dapat disimpulkan atas pelaksanaan kegiatan adalah sebagai berikut :

a) Potensi dan prospek usaha pengolahan nugget dan sosis ikan patin cukup baik untuk dikembangkan karena bahan baku yang cukup tersedia di Banjarmasin, memiliki tingkat keuntungan usaha yang cukup baik serta peluang pemasaran masih terbuka lebar.

b) Mitra PKM telah dibekali dengan pengetahuan, ketrampilan dan sarana produksi yang cukup untuk memulai usaha di bidang pengolahan nugget dan sosis ikan patin.

c) Tim PKM akan tetap memberikan pendampingan pemasaran dan pengurusan perijinan yangdiperlukan untuk menjalankan usaha pengolahan nugget dan sosis ikan patin. 
d) Para peserta kegiatan cukup antusias dan tertarik untuk mengembangkan usaha di bidang pengolahan nuggetdan sosis ikan patin.

e) Masih adanya kendala berupa daya listrik panti yang terbatas sehingga freezer untuk display dan penyimpanan produk belum bisa secara kontinu dioperasikan.

\section{Saran}

Berdasarkan hasil kegiatan, maka dapat disarankan untuk kegiatan PKM selanjutnya adalah perlu kiranya memperhitungkan kapasitas daya listrik panti guna menunjang kegiatan pengolahan nugget dan sosis ikan patin serta memasukkan kegiatan renovasi dapur panti yang akan dijadikan sebagai tempat pengolahan agar proses pengolahan tetap dapat dilaksanakan secara higienis.

\section{DAFTAR PUSTAKA}

Bapeda. 2012. Kajian Pengembangan Industri Kerakyatan di Kecamatan Banjarmasin Utara. Laporan Hasil Penelitian. Kerjasama Bapeda Kota Banjarmasin dengan Lembaga Penelitian Universitas Lambing Mangkurat. Banjarmasin.

BKPMD Kalsel. 2014. Potensi Perikanan Kalsel. http://bkpmd.kalselprov.go.id/ind ex.php/ artikel/potensi/perikanan. Diakses tanggal 29 Mei2017.

BPS. 2016. Banjarmasin dalam Angka 2016. Biro Pusat Statistika Kota. Banjarmasin

\section{Statistik Daerah}

Kecamatan Banjarmasin Utara 2016. Biro Pusat Statistika Kota Banjarmasin. Banjarmasin.

\section{Kecamatan Banjarmasin}

Utara Dalam Angka 2016. Koordinator Biro Pusat Statistika Banjarmasin Utara. Banjarmasin.

Nafiah, H., Pratjojo, W., \& Susatyo, E. B. (2012). Pemanfaatan Karagenan dalam Pembuatan Nugget Ikan Cucut. Indonesian Journal of Chemical Science, 1(1).

Ramasari, E. L., Ma'ruf, W. F., \& Riyadi, P. H. (2012). Aplikasi karagenan sebagai emulsifier di dalam pembuatan sosis ikan tenggiri (Scomberomorus guttatus) pada penyimpanan suhu ruang. Jurnal Pengolahan dan Bioteknologi Hasil Perikanan, 1(1), 1-8.

Purnomowati. I dan D. Hidayati. 2012. Aneka Kudapan Ikan. Edisi 8. Penerbit Kanisius. Yogyakarta.

Purnomo, dan Suhanda, J. 2014. Diversifikasi Olahan Berbasis Ikan Patin Di Desa Jingah Habang Hilir Kecamatan Karang Intan Kabupaten Banjar Kalimantan Selatan. Fish Scientiae. Volume 4 (8): 80-94. 